\title{
Health Needs Above of Automation Fears: The Role of the Future of Work in Shaping Career Decisions and Appraisals of Employment Among Young Adults with Disabilities
}

Arif Jetha ( $\nabla$ ajetha@iwh.on.ca )

Institute for Work \& Health

Ali Shamaee

Institute for Work \& Health

Emile Tompa

Institute for Work \& Health

Peter Smith

Institute for Work \& Health

Ute Bultmann

University of Groningen

Silvia Bonaccio

University of Ottawa

Lori Tucker

British Columbia Children's Hospital

Cameron Norman

Cense LTD

Cristina Banks

University of California Berkeley

Monique Gignac

Institute for Work \& Health

\section{Research Article}

Keywords: Future of work, disability, young adults, changing nature of work, digital transformation, precarious work, precarious work, automation

Posted Date: July 6th, 2021

DOI: https://doi.org/10.21203/rs.3.rs-639354/v1 
License: (c) (i) This work is licensed under a Creative Commons Attribution 4.0 International License. Read Full License

Loading [MathJax]/jax/output/CommonHTML/jax.js 


\section{Abstract}

Objectives. Technological, sociopolitical and environmental forces are changing the working world and creating conditions that could be disadvantageous to young adults with disabilities. Our study aims to examine the thoughts and perceptions held by young adults with disabilities regarding the future of work.

Methods. One-on-one semi-structured interviews with Canadian young adult (ages 18-35 years) with a disability were conducted. Participants were asked questions on their thoughts and perceptions regarding the impact the changing nature and availability of work on their labor market involvement and career aspirations. Themes that emerged from the data were inductively examined.

Results. Twenty-two young adults were interviewed of which just over half were employed full-time. Career aspirations and work-related decisions were primarily shaped by a participant's health needs. Aspects of the future of work were seen as a more proximal determinants to employment. Digital technologies were expected to impact working conditions for people with disabilities and create barriers and facilitators to employment. Participant who were securely employed held positive expectations regarding the impact of digital technology on their work. Conversely, participants working precariously held negative appraisals regarding the impact of digital technologies on employment opportunities.

Conclusions. Initiatives that support labor market engagement of young adults with disabilities should consider changes in the future of work and emerging health needs while also accounting for the availability of secure work arrangements.

\section{Background}

The future of work, characterized by large-scale interrelated technological, sociopolitical and environmental trends, is expected to drastically transform the working world and, despite potential benefits, contribute to employment and health inequities in the working population (1-3). Few studies have examined how specific subgroups of workers may be disadvantaged by the changing nature of work. Our study focuses on the thoughts and perceptions held by young adults with disabilities regarding the future of work. Past studies show that young adults with disabilities experience barriers to entering and advancing within the labor market compared to their peers without disabilities, and these barriers have been attributed to their disability and the characteristics of the work context (4). The future of work may alter conditions with which young adults with disabilities work and that permit person-job fit and long-term engagement in the labor market. Through a qualitative research approach, our study examines thoughts and perceptions held by young adults regarding the future of work that may intersect with the experience of living with a disabling health condition and being at the early career phase.

A growing body of research within industrialized countries shows that the future of work encompasses a diverse set of forces that are expected to disrupt every industry, disrupt every industry, change work conditions and impact the types of availability of job $(1-3,5)$. The digital transformation of the economy 
and application of diverse digital technologies - such as artificial intelligence (Al) and machine learning systems, advanced robots, smart sensors, Internet of Things, blockchain technology or self-driving vehicles - are occurring at a faster pace compared to past periods of technological adoption and are resulting in significant change to the world of work (6-8). However, it is important to acknowledge that not all changes in the future of work are related to technology. Social (e.g., generational changes in the workforce), political (e.g., growing populist sentiments) and environmental changes (e.g., climate change and the green economy) are also impacting the nature of work and have significant implications for different groups of workers $(1,2,9)$. Recent studies indicate that the COVID-19 pandemic has accelerated the advancement and adoptions of different digital technologies, contributed to displacement of some workers and has widened employment inequities across the working population (1).

Studies indicate the future of work is associated with new opportunities for the working population including the creation of new occupations and increased demand for workers with advanced technical and soft job skills (10). Other research highlights potential disadvantages in the future of work, including an erosion of standard employment opportunities (e.g., full-time permanent jobs) and a rise in nontraditional and contingent employment (e.g., freelancing and gig work). Of specific concern, recent studies indicate that the future of work may be fragmented (9). Some groups of workers, especially those precariously employed and in lower-skilled jobs with repetitive tasks, may be more likely to be negatively affected by growing the application of technology that automates work $(11,12)$. Continued advancement of technologies may also mean that workers in higher-skilled jobs could also be displaced in the future of work. Given the scope of change expected and the potential for its changes to contribute to inequities in the labor market, the future of work may play a significant role in determining an individual's socioeconomic position and mobility, and exposure to risk factors for physical and mental health in the working population $(13,14)$.

One group of labor market participants who may be particularly affected by changes in the future of work are young adults with disabilities. In Canada, where the current study was conducted, close to two million youth and young adults live with a disability that contributes to activity limitations and social role participation restrictions. Studies indicate that a disability can impact entry and advancement in the world of work, as well as career aspirations (15). For instance, population-level data from Canada shows that the employment rate of youth (18-24 years, 32\%) and young adults (25-35 years, 54\%) living with a disability is significantly lower than their counterparts without a disability ( $52 \%$ and $82 \%$, respectively) (15). Studies indicate that young adults with disabilities who are employed are more likely to report fewer work hours, lower income, more lost productivity, and greater barriers to career advancement than their non-disabled peers $(4,15-17)$. At the same time, new digital technologies could result in some benefits to employment and address barriers to inclusion within the working world (e.g., opportunities to for workfrom-home) (9). Limited research has examined how the future of work will impact young adults with a disability. A small number of studies of people not living with disabilities show that young adults may be more likely to be affected by the digital transformation of the economy than compared to other age groups. Compared to middle-aged and older adults, young workers are likely to enter the labor market Loading [MathJax]/jax/output/CommonHTML/jax.js re likely to be automated and are disproportionately more 
likely to rely on a digital platform to obtain paid work $(12,18)$. For young adults, a disability has the potential to exacerbate vulnerabilities within the future of work.

Through in-depth interviews conducted with Canadian young adults living with disabilities, our study addresses two overarching objectives which include to: 1 ) examine the perceptions held by young adults with disabilities regarding their work history and their long-term employment prospects; and 2) determine if there are aspects of the future of work that would change the labor market experiences of adults with disabilities. Findings from this study can inform the design of strategies that are resilient to the future of work and can support employment entry and advancement of young adults with disabilities.

\section{Methods}

We conducted one-on-one interviews with young adult Canadians (ages 18-35 years) who reported having a health condition that contributed to activity limitations. To capture breadth and depth in thoughts and feelings regarding the future of work, we aimed to recruit participants who differed according to gender, disability type and employment.

Interviewees were identified through an existing cohort of young adults with disabilities who participated in a previous study on school-to-work transition and had consented to be contacted for future research (4). Email invitations and a study background were sent to potential participants. Interested participants were asked to contact a member of the research team to confirm eligibility, provide informed consent and schedule an interview. The interview process began in February 2020, and a rolling recruitment strategy was taken with additional participants recruited to address emerging themes. As an example, our study was conducted at the early stages of the COVID-19 pandemic where lockdown orders were being implemented to control COVID-19 transmission. Additional interviews were conducted to capture emerging themes related to the impact of lockdown restrictions and policies that addressed the occupational spread of COVID-19. Participant recruitment occurred until no new themes emerged from the interviews (19). Participants received a $\$ 25$ honorarium for their involvement. To protect confidentiality, personal identifying information was removed from interview transcripts and all participants were assigned a unique ID number. Study procedures were cleared by the research ethics board of the University of Toronto (REB\# 38706). All data collection and analysis were performed in accordance with research ethics guidelines and regulations for human subjects.

\section{Interview questions}

Interviews were semi-structured and conducted over the phone. Interviews began by asking participants about their past experiences entering and advancing within the world of work with a disability. Specific questions were then asked about a participant's career aspirations and how having a disability could impact their ability to meet career goals. Participants were also asked questions on their thoughts and perceptions regarding the future of work, including the role of digital technologies, changing nature and availahilitv of work and the role of coninnolitical and environmental conditions on their future Loading [MathJax]/jax/output/CommonHTML/jax.js 
involvement in the labor market and ability to meet career aspirations. All interviews were recorded and transcribed verbatim. A research coordinator checked all transcribed data for accuracy.

\section{Data analysis}

Our study took a constructivist perspective $(20,21)$. We inductively examined themes that emerged from the data to build an understanding of the future of work for young adults with disabilities (20). Transcripts were reviewed by three members of the research team, and an initial codebook was collaboratively developed and revised through several iterative collaborative conversations. Utilizing the codebook, two transcripts were coded by four investigators to ensure dependability. The codebook was refined through additional discussions with the investigative team and applied to the analysis of the remaining transcripts. A primary and secondary coder conducted comprehensive line-by-line coding of transcripts. Once coding was complete, prominent themes were extracted and specific codes nested within each theme were identified. Throughout the analytical process, codes and themes emerging from the data were discussed in analysis meetings with some members of the investigative team at which time any inconsistencies were resolved by consensus. Our analysis leveraged expertise from a multidisciplinary research team with expertise in qualitative research methods and a background in industrial and organizational psychology, economics, medicine and public health, occupational health, public policy, organizational behavior and human resource management. All coding and thematic analysis were conducted using the software program NVivo (22).

\section{Results}

We interviewed 22 young adult participants (age range 24-36 years). Close to two-thirds of participants (64\%) identified as women and one participant identified as non-binary. At the time of the interview, 55\% of participants worked full-time ( $\geq 30$ hours/week), $27 \%$ worked part-time hours ( $<30$ hours/week), and $18 \%$ reported not working or being furloughed as a result of the COVID-19 pandemic. Over half of participants indicated a physical disability (55\%), and $45 \%$ reported a mental health or cognitive disability.

We identified two thematic categories which contained multiple subthemes. The first thematic category was related to career aspirations and work-related decisions. When asked about the future of work, young adults with disabilities who participated in our study described that health was the primary determinant of career decisions rather than changes to the nature and availability of work. Accordingly, most participants indicated that their career aspirations and work-related decisions were primarily shaped by their health needs and changes to the nature of work were seen as a more proximal determinant to their ability find and sustain employment. Within this thematic category, participants highlighted issues around health uncertainty, whether they anticipated long-term sustainability of work, the availability and need for supports and accommodations, and the importance of job security to reduce stress and help meet health needs. 
The second thematic category was related to the role of digital technologies in transforming working conditions for young adults with disabilities. Participants described how advanced digital technologies could impact their working conditions and create barriers and facilitators to employment Within this theme there were parallels to the first theme in that issues of long-term changes and sustainability were discussed, the availability of workplace supports and additional training, and the job security afforded (or not) by technology. Participants also discussed issues of person-job fit and hard and soft job skills needed in the future of work. The following sections examine key findings in greater depth.

Thematic Category A. Young adults with disabilities reported that career aspirations and work-related decisions were more likely to be shaped by health needs and expectations, not changes in the future of work

For young adult participants who were living with a disability, discussions on the future of work centered on career aspirations they held and longer-term employment expectations. Despite including multiple probes in our interview guide regarding how the nature and availability of work could change, there was a general hesitation for participants to think about their working life too far into the future. Instead, most participants anticipated that their health would worsen over time or their disability would contribute to a greater number of activity limitations that would restrict employment participation in ways that met their career goals. Accordingly, participants reported that they were less likely to feel that different trends that characterize the discourse on the future of work could impact their career in the long-term. For instance, one participant who lived with a mental health disability and was employed in multiple part-time jobs at the time of the interview reflected on perceptions of the future and noted that:

"It's difficult for me to think about the future because I used to make plans and then life would go in very unexpected ways, so I just stopped. I'm trying [to] re-grow that part of myself, the part that can sort of make plans and try and think about the future, but it's really hard to re-grow something that you've killed again and again for years." - Participant ID\#164

Participants tended to take a shorter-term perspective towards their career and prioritized the management of their disabling health condition when making employment decisions. These decisions were often directly tied to the characteristics of their health condition. Among participants who were able to find employment that was well-suited to their health needs, there was hesitancy to leave their current job even if that meant they were not pursuing their career aspirations. One participant living with a mental health disability who was not working at the time of the interview highlighted their goal of finding employment that could support a health condition that fluctuated in severity.

"I know that my health can fluctuate a lot in a year, it goes from feeling fine to not several times over a year. Because it's unpredictable it can affect everything. It can affect how well I can look for a job and how well I can perform at a job. It could have a big impact. I also think that the wrong job could ... if I was in a job that was too high stress or they're not accommodating enough, it could make mental health worse just on its own." - Participant ID\#128

Loading [MathJax]/jax/output/CommonHTML/jax.js

Page $7 / 20$ 
The requirement to find work that supported health in the future was exacerbated for those with a disabling health condition that was described as progressively worsening over time. One participant who held a full-time permanent job at the time of the interview and was living with a physical disability held expectations regarding worsen health over time, finding a job that offered workplace supports was the most important career goal. The same participant described hesitancy about leaving their current job in order to pursue career aspirations.

"...my disability is one that progresses with time. I will get weaker as time goes on. That obviously is something I have to think about [when making career-related decisions]. Will my job continue to be flexible in that way? Like I said, I think it would be very hard for me to want to leave this [job] and go to another job not knowing how they [employer] would treat this type of situation." -Participant ID\#117

Participants repeatedly described specific job characteristics that would support their health and informed the types of jobs they aspired towards obtaining. Most participants, especially those with a disability that had more complex treatment and self-management requirements, emphasized the importance of obtaining a job with security and where workplace supports were readily available (e.g., job accommodations, scheduling flexibility, health benefit plans). Relatedly, participants also talked about the importance of finding employment within certain sectors (e.g., banking, public service, health care) that are perceived as offering more accessible working conditions for people with disabilities. For example, one participant with a physical disability who was employed in a permanent full-time job at an academic institution described the importance of employer-provided drug plan in shaping career decisions.

"Yeah, I can't [think about leaving current employment]...If I ever were to apply to a job at a different corporation or university, I would have to first ask, do their benefits package cover the [drug] for the amount that I have, and covers not things that aren't pre-existing, that existed after the fact... It makes it a little bit more pointless to even apply to jobs if I know that's the case, so I've more or less have had to resign myself to continue to work at my institution as it stands." - Participant ID\#102

Young adult participants in our study emphasized the importance of selecting and retaining a secure job with workplace supports to sustain employment with a disability. At the same time, access to secure employment was affected by labor-market conditions in an economy where employers are increasingly reliant on gig workers to complete job tasks. In particular, participants frequently described that the availability of secure employment arrangements was decreasing (e.g., full-time permanent work). Contingent employment arrangements (e.g., shorter-term contracts, seasonal work, gig work, freelancing and microtasks) were more commonly available. Of note, participants expected that the likelihood of working in a contingent arrangement stemmed from the growing adoption of digital technologies that automated job tasks or an increasing number of apps being used by companies that facilitated access to short-term contracts. One participant described working as a customer service representative where job tasks were increasingly being automated and there was increasing competition for a limited number of shifts. The same participant described the desire for greater job security and scheduling predictability. 
"Things gradually improve and then what's good one week it can revert back to something bad the following week. We were getting more projects overall at the [company name], like my company, who are third party for [company name]. But now one of the projects is going to end. So, then all those people are basically out of work so I'm going to be competing against them for the finite number of shifts that are available left. So, me getting four shifts a week it's not likely anymore. I may only get two shifts a week and then that affects your income. And then at that point you're like why I should stick it out with this job. Where can I go to another job and get five days a week guaranteed every week?" - Participant ID\#121

Some participants felt that having a disability meant that they were more likely to be excluded from secure employment arrangements compared to their peers not living with a disability. As a result, they may be more likely to be forced to work contingently. It is important to highlight that some participants acknowledged that contingent work arrangements could offer some benefits for people with disabilities including an opportunity to enter the labor market and obtain work experience or scheduling flexibility that could support their health. However, for the most part, participants tended to describe negative consequences of contingent work such as exclusion from legislative protections, not having access to workplace supports or feeling that their employment was precarious in comparison to those working securely. One participant in a full-time permanent job with a physical disability reflected on the implications of the gig economy for people with disabilities.

"A lot of times, the gig economy is seen as a good thing, that maybe it will actually include people with disabilities furthermore. I'm sure that's about the reality too. But I actually think the gig economy could be quite dangerous for people with disabilities, the inclusion of people with disabilities specifically, partly because right now accommodations are enshrined in [employment legislation] So, when you move into a gig economy, you are no longer an employee, you are a contractor.".- Participant ID\#101

Participant's career aspirations were less likely to shaped by changes in the future of work. Instead, workrelated decision-making was largely driven by need to support health but constrained by access to secure employment arrangements. At the same, participants all highlighted that technology was affecting the way they performed their jobs and would change employment conditions in the future.

Theme B. Digital technologies could transform working conditions for young adults with disabilities and change the requirement for specialized job skills

The digital transformation of the economy was considered by participants as the most predominant factor that could change working conditions in the future. Participants described examples of technology that they encountered within their existing work that had affected their employment, such as Al systems, cloud computing, Internet of Things devices and virtual reality. Advancements in existing digital technologies and the emergence of new technologies were described by participants as having both potential opportunities and barriers for people with disabilities. For instance, participants often noted that certain digital technologies could be used as a tool to provide greater flexibility to work schedules and job task performance, support work-from-home arrangements and reduce physical job demands. 
Participants who worked securely in white-collar jobs were more likely to hold positive evaluations regarding the impact of digital technology for people with disabilities compared to those in contingent employment. For example, one participant who worked full-time described the benefits of digital technologies in enabling work-from-home arrangements to improve accessibility for people with disabilities:

"...if there's more advances in technology where people can have the same software they're using at work and being able to use that at home, I think it will give, especially for people with disabilities, more opportunities to be able to have a job and keep a job. Like, with our company right now, they're looking at options for cloud software for us to use from our computers...I think facilitating work at home, maybe access to other spaces that wouldn't normally be accessible to people otherwise... - Participant ID\#173

Interestingly, the role of digital technologies on long-term employment was often discussed within the context of the COVID-19 pandemic which was ongoing at the time of the study interviews. Participants who were securely employed noted that their workplaces increased the provision of digital platforms to facilitate work-from-home arrangements in response to COVID-19 lockdown orders. The opportunity to perform job duties from home was seen by participants as an important change to their working condition that enabled them to manage their health needs. One participant living with a physical disability noted how the implementation of digital technology in response to the COVID-19 pandemic had important implications for their employment accessibility. At the same time, the participant indicated frustration regarding being denied similar accommodations in the past.

"I think that's the number one important thing, to have good technology for all these companies, to be able to accommodate all of their employees. For example, during that time when I was looking for a job and I applied to places and I would ask them about options for working from home, a lot of them would say, oh, no, we don't do that. But now, with this virus that is happening, almost everyone is working from home and I know a lot of those companies have employees that are working from home right now. I'm like, oh, was it just because of my disability, that you didn't want to hire me, or you just weren't thinking ahead in that kind of way at that time? It's something that I was thinking about because I feel like it's very easy for a lot of companies to do this. I think technology is very important." - Participant ID\#117

However, digital technology was not seen as beneficial to all participants. Participants who were employed in contingent work or not employed at the time of the study reported more concerns about the application of digital technology to the working world and on their ability to sustain employment in the long-term. Participants who indicated that their employment was precarious described automated devices (e.g., digital kiosks) or Al-enabled systems (e.g., chatbot customer service representatives) as examples of digital technologies that reduced their availability of shifts, decreased the number of job tasks for which they were responsible and increased competition for a limited number of positions. Also, participants who were employed in contingent arrangements felt that advancements in the development and application of different digital technologies within their workplaces would continue to negatively imnant their emnlovment nver time and nontribute to greater precarity or displacement from the labor Loading [MathJax]/jax/output/CommonHTML/jax.js

Page 10/20 
market all together. For example, one participant working precariously in the service industry highlighted perceived risk of work being automated:

"I don't think technology would be a good thing in my job because...customers could interface with a computer screen and it tells them everything they want to know. What use are us to be there? We're dispensing information. The more technologically advanced things get it's the less likely they'll [employer] need us. Even the [fare] collectors, there's no more collectors in the [company] anymore because they've been phased out because of [digital payment systems]. Technology is a good thing but then...it's a bad thing too because you need that human connection sometimes that's kind of missing when you just deal with a robot" - Participant ID\#121

Within the context of the intersection between digital technology and contingent employment, several participants indicated the importance of employer- or policy-level supports to protect people with disabilities from being negatively affected by the increasing use of digital technologies. For example, one participant noted that despite employer investments in the design and application of digital technologies there should be workplace policies and managerial practices that provide job security and support to workers with disabilities.

"I think that technology can only do so much if those technological advances are not paired with structural and institutional attitudes of accessibility and... When I look at technological advances, they seem to mostly prioritize an ethic of productivity. And so, when it comes to disabled workers, technological advancement help business and help employers because now disabled workers can be just as productive as a non-disabled worker. And absolutely when disabled people, we live precarious lives and we don't know what our future will look like in terms of our income, and our access to social benefits are very limited in this province. We want to be working and we want to feel secure in that work." -

\section{Participant ID\#169}

The increasing reliance on machines to automate work tasks was described as creating an opportunity within workplaces that can be filled by human workers. Several participants noted that human workers, especially those with a disability, can make important contributions to the work environment. Additionally, some participants also downplayed the risk of automation to their employment. Instead, fears of machines replacing employment opportunities in the future was downplayed in circumstances where a person was working in a job where they felt that their health was supported.

"I mean, a robot could definitely do a good chunk of my role, but, at the end of the day, I have to gain more strategic leverage to, sort of, overcome that...The people operations is always going to be a factor. I mean, you see bank tellers and the ATM machine coming in, and, yeah, it took some jobs, but now, they phased it, work on client management. I'm not too worried, but I'm not...like, as long as I'm not in an environment where it's high stress, high pressure. That is the only thing I worry about..." - Participant ID\#146

Stemming from reflections on the digital transformation of the economy, interview participants evaluated ssed and the types of jobs they anticipated to emerge in the 
future. A majority of participants indicated that having, at the minimum, a baseline level of digital literacy would provide an entry point to the workforce. As an example, one participant who was not working at the time of the interview described that a major goal was to find employment with a start-up company. They described the requirement to possess digital literacy and obtaining coding skills to compete for available entry level jobs in start-ups that were increasingly becoming more reliant on digital technologies. They noted that:

"A lot of people start as some type of data analyst...A lot of start-ups look for people who just know Python, or even know basic web development, so I had to learn a little bit of HTML and CSS along the way...I do see the utility of having a tangible and hard skill. Because university teaches a lot of soft skills...But, again, it's not even about the piece of paper [referring to a university diploma], it's about being able to utilize it, like, utilize the skills that they teach you." - Participant ID\#137

Other participants described that digital technologies were changing at a rapid rate, and it was important to continue building more complex technological skills to access career advancement opportunities and avoid being made redundant in the working world. For instance, one participant working in the information technology field at the time of the interview described the need to keep up with new and emerging digital technologies through online courses.

"Some of them [courses] are paid, of course, not everything, but there are a lot of free resources, webinars and seminars and stuff. I am up to date, to be honest. Right now, $5 \mathrm{G}$ technology is coming, for instance. I've been in the $5 \mathrm{G}$ webinar just a couple of days ago...If you don't keep up with technology advancement, you're pretty much done, you're out of the technology land." - Participant ID\#193

Along with the development of technological job skills, participants acknowledged that soft skills (e.g., communication, critical thinking and collaboration) were also valued by employers. Building soft skills could enable young adults to provide uniquely human elements to workplaces that were increasingly relying on digital technology. However, the ability to develop and implement soft skills could be limited for people with disabilities who face psychosocial barriers in the work environment. Some study participants reported being more likely to feel socially excluded within the workplace and less likely to obtain opportunities to develop teamwork skills. For example, one participant in a full-time position at a financial institution described the barriers faced to developing soft skills and the steps to address those barriers.

"I'll take on sort of advisory positions and that's my way of improving my softer skills, which I think sometimes that's been also a challenge sometimes in the people with disabilities. Because often some people with disabilities take extreme social isolation. And that makes it challenging to develop your social skills, which are honestly in the future of work seems to be a bigger thing than an actual degree. I think that's also a barrier. So, I'm always doing a bit of that as I grow in my career and making sure that I spend time and learning how to articulate my job in effective communication." - Participant ID\#101

Challenges in obtaining job skills were also frequently attributed to the demands associated with living e that was directed towards the management of health (e.g., 
resting, being physically active, attending healthcare appointments). Other participants indicated that certain types of disabilities like those with mental health or cognitive limitations contributed to difficulties learning new job skills. For instance, one participant reflected on how a mental health disability made obtaining a post-secondary education challenging. Based on previous experience, the participant noted that obtaining new skills to compete for jobs of the future would be difficult.

"I finished university a year and a bit ago. And it was very difficult. Originally, when I went into university, I was planning on doing an undergrad and then training to be an occupational therapist. A few years into university, that just had to go, because I could barely finish my BA. And once I was done that, I mean you have no idea the number of all-nighters I pulled to try and get my brain to think the way I needed it to. I was mush by the end of it. So, I couldn't really think about doing other school. Now, I'm not mush anymore, so maybe one day, but it's still pretty closed. I wouldn't rule it out completely, but also it's difficult to think about." - Participant ID\#164

Relatedly, work arrangements at the time of interview frequently determined the extent to which a participant felt that they could obtain both technological and soft job skills needed for career advancement. For instance, participants employed in contingent work often indicated having a weaker connection to the workplace and felt that their employers were less likely to provide them with job skills development opportunities. On the other hand, participants working securely were more likely to indicate access to employer-led job skills development opportunities. For instance, one participant who was securely employed in the publishing industry described the provision of training opportunities from their employer so that they could keep up with technological changes within their industry. They noted that:

"Yeah, lately one of the appealing things about this company that I've come to was that they give a yearly stipend that you can put towards education. One of the big things in my industry, as much as I talk about how much I love books and the printed books and all this stuff, there's also been a big movement towards data and data analysis and trend patterns and that kind of thing. I have had it in my head, taken a few classes this last year looking at computer science and statistics, things like that". - Participant ID\#120

Overall, digital technology was seen as the most prominent driver of change to the nature and availability of work in the future. Perceptions regarding the impact of technology on employment and opportunities to obtain necessary job skills for the future of work were related to whether or not a participant reported a secure work arrangement.

\section{Discussion}

The future of work has important implications for young adults with disabilities as they enter and advance within the labor market. Through study interviews, we found that young adults living with disabilities may be less focused on how the changing nature of work impacts their employment and, instead, may direct their attention towards the management of their health needs. The digital transformation of the economy has the potential to disrupt person-job fit and contribute to greater Loading [MathJax]/jax/output/CommonHTML/jax.js the requirement for specialized job skills. Those holding 
contingent employment may be more likely to be adversely affected by digital technologies and may have limited access to job skills development opportunities. Our findings have public health implications. Challenges participating in the future of work can create unpredictability in sustaining employment and accessing resources (e.g., income, job accommodations and health insurance) that support health (13, $14,23)$. Strategic thinking is required to consider the intersection between personal and health-related needs in the design of initiatives that foster employment in the future of work and are tailored to the needs of young adults with disabilities.

Our study is one of the first to interview young adults with disabilities on their thoughts and perceptions regarding the future of work. Interestingly, study participants were less likely to think about how different aspects of the future of work could impact their ability to enter and advance within the working world. Participants were more likely to emphasize how their health or involvement in different social roles would impact their long-term employment. Our findings align with past studies showing that young adulthood is an important transitional phase where a person may make multiple occupational and life changes with the goal of finding full-time permanent employment that meets career goals and can offer opportunities for career advancement (24). Having a disability adds to the complexity of this life phase and may contribute to a young person placing a greater emphasis on making work-related decisions that prioritize the management of their health needs (25). Accordingly, when compared to their peers without a health condition, young adults with disabilities may be less likely to focus on the broader range of long-term changes related to the future of work that could directly or indirectly impact their employment. At the same time, our study aligns with growing research that emphasizes the importance of employer-provided accommodations to address barriers to inclusion for young adults with disabilities as they enter the working world (4). Our study brings to light a potential disadvantage facing the young adults with disabilities that we interviewed; a focus on shorter-term work decisions may facilitate entry into the working world but also pose barriers to career advancement and participation within a labor market that is rapidly changing. Additional research comparing young adults with and without disabilities on thoughts and perceptions of the future of work represents an important future research direction.

Digital technology was recognized by participants with disabilities as an aspect of the future of work that would have a significant impact on their long-term employment. The advancement of diverse digital technologies are shifting the division of labor between human workers and machines $(1,7)$. For young adults with disabilities, this shift in the division of labor may substantially impact physical and psychosocial job demands and perceptions of job control and significantly alter aspects of the work environment with which they are exposed. Of interest, for participants in our study, existing work arrangements were associated with the perceptions they held regarding how digital technology could impact employment. Study participants working in contingent employment were more likely to indicate that digital technology would contribute to greater job insecurity, result in job displacement and increase competition for limited number of full-time and permanent employment when compared to those who held secure employment. Recent analyses show that contingent employment is an increasingly common feature of the labor market, especially for youth and young adults and people living with disabilities (26, Loading [MathJax]/jax/output/CommonHTML/jax.js can employment in contingent work limit access to resources 
to support health (e.g., living wages, health insurance, paid sick leave, pension plan, social support) it can also increase susceptibility to automation $(11,14)$. These trends were felt acutely by our participants. Moreover, advancements in Al and machine learning systems coupled with accelerated employer investment in digital technologies in response to the COVID-19 pandemic have the potential to exacerbate precarity for young adults with disabilities who hold a contingent work arrangement, widen health and social inequities and give rise to novel barriers and facilitators to employment $(1,28-30)$. Our study provides a foundation for additional research to examine the impact of emergent digital technologies on the employment of young adults with disabilities. Building insights on the impact of digital technology on the employment of people with disabilities and other vulnerable groups is essential to informing the design of policies and practices that offer employment protection and can mitigate potential health consequences.

Participants who indicated being securely employed were more likely to describe how technology would enable job performance and increase employment accessibility when compared to those in contingent work arrangements. A recent synthesis of evidence describes how different digital technologies could address the barriers to employment reported by people with disabilities. In particular, digital technologies can provide scheduling flexibility (e.g., virtual telework platforms), address physical limitations (e.g., smart manufacturing robots) or automate repetitive tasks (e.g., self-driving cars) $(6,31)$. The use of digital technology within workplaces can help to eliminate barriers to inclusion for people with disabilities within the labour market and be used to meet the requirements of recent international (e.g., UN Convention on the Rights of Persons with Disability (32)) and country-level disability accessibility legislation (e.g., Accessible Canada Act (33)). Based on the findings of our study additional research is required to examine ways in which digital technology can be leveraged for young adults with disabilities who could be entering employment in secure or contingent work arrangements. Additional research may be especially important within a world of work that is increasingly reliant on Al-enabled applications used for human resource management (e.g., job selection and performance management) whose development and use of complex algorithms have the potential to introduce and reinforce biases against people with disabilities as they transition into work (9). Employers and policymakers should be encouraged to develop policies and programs that ensure equitable applications of digital technologies on diverse groups of workers and direct supports to those working in jobs most likely to be disrupted by digital technologies in the future.

Related to discussions on the impact of digital technology, participants noted that the future of work was associated with the requirement to obtain specialized technological and soft skills to obtain jobs of the future, complement job tasks being performed by machines and advance within their careers $(10,34)$. Yet, having a disability as a young person can create unique barriers to accessing skilling opportunities. These challenges could be exacerbated for those in contingent work who may be less likely to access employer-led job skills training. Our interview findings can be contextualized within existing labour-market studies which project a significant shortage of workers who possesses job skills most required by employers $(3,35)$. For instance, Canadian data estimates that by 2031 there will be a shortage of two Loading [MathJax]/jax/output/CommonHTML/jax.js hnological skills (35). Not surprisingly, upskilling and 
reskilling initiatives have been a major focus of policy and programmatic development aimed to prepare the workforce for the future of work $(10,36)$. The extent to which people with disabilities are included in the design and implementation of these initiatives is unclear. Of specific concern, challenges to upskilling and reskilling has the potential to contribute longer-term exclusion of people with disabilities from higher quality employment. Additional research is required to understand how to adapt the design of job skills training initiatives for people with disabilities and identify strategies so that they are accessible to a broader subset of the working population.

Our study findings can be contextualized through the lens of a person-job fit model. Past studies show that the fit between a person (e.g., physical and mental job demands, working conditions requirements) and their job (e.g., job-related knowledge, skills, abilities, experience a person holds) can affect the appraisals they hold towards their employment participation (e.g., job strain, career satisfaction, job engagement), determine their job performance (e.g., productivity) and career advancement and personal well-being (37-39). Past studies also indicate a disability can be associated with restrictions to acts that can disrupt the fit between a person and their job (40). The future of work has the potential to disrupt person and work environment characteristics that affect the employment for young adults with disabilities. Drawing from a person-job fit model, our research underscores the importance of innovative strategies for young adults with disabilities that promote job skills acquisition and encourage job-related behaviors that may be undertaken within the boundaries of contingent work arrangements and can enable career advancement within the future of work. At the same time, steps at the employer-level and at the policy-level should also be implemented to ensure that changes to the work environment and broader labour-market conditions do not disproportionately disadvantage young workers with disabilities and other vulnerable groups.

A strength of this study is the inclusion of a diverse group of Canadian young adult participants living with disabilities employed in secure and contingent work arrangements and who provided depth and breadth in their thoughts and perceptions regarding the future of work. Also, our research team consisted of investigators from a range of different disciplines who provided a unique lens to the research that was applied to our iterative coding process and interpretation of key themes that emerged from the data. At the same time, it is important to acknowledge that thinking about work-related challenges and opportunities from a future-facing perspective could be challenging for young adults with disabilities. Accordingly, the impact of the future of work may only be truly realized over time as participants are exposed to different technological, sociopolitical, demographic and environmental trends. To address this limitation, we suggest that subsequent research should draw on methodologies in the field of future studies and draw on participatory approaches to build potential scenarios regarding the future of work for people with disabilities (41). Moreover, these studies could enable the generation of policy and programmatic recommendations that are future-oriented and well-suited to the needs of people with disabilities.

\section{Conclusion}

Loading [MathJax]/jax/output/CommonHTML/jax.js

Page $16 / 20$ 
The future of work can shape the work experiences of young adults with disabilities as they transition into the labor market. Our qualitative study suggests that having a disability may limit the extent to which individuals consider various external trends that characterize the future of work. While technology is changing the ways in which work is performed and requirement for specialized job skills, the benefits may only be realized by those in more secure employment arrangements. This is a critical finding, because being excluded from the future of work can play a significant role in determining health and social inequities for the working population living with a disability. As such, our study has important population health implications. Subsequent research to understand how different aspects of the future of work can result in the inclusion or exclusion of young adults with disabilities is needed.

\section{Abbreviations}

$\mathrm{Al}=$ artificial intelligence

\section{Declarations}

\section{Ethics and consent to participate}

Study protocol was reviewed by the University of Toronto research ethics board (REB\# 38706). All study participants will provide written informed consent and all findings are presented in anonymized form.

\section{Consent for publication}

All authors consent to publishing this manuscript.

\section{Competing interests}

$\mathrm{CN}$ is the principal and president of Cense LTD. CN has no financial or personal conflicts of interest related to the study. No other authors have competing interests related to this research to report.

\section{Funding}

This study is funded by a New Frontiers in Research Grant from Canada's Tri-Agency Programs Secretariat. The study protocol has undergone peer-review by the funding body. The funding body was not involved in study design. In addition, the funding body will not be involved in data collection and study design, interpretation of data and manuscript writing.

\section{Availability of Data and Materials}

The datasets generated and/or analysed during the current study are not publicly available due to protect the privacy of research participants as outlined in the study's research ethics protocol but are available from the corresponding author on reasonable request. 
Arif Jetha: Conceptualization, Methodology, Formal analysis, Writing - Original Draft, Funding acquisition

Ali Shamaee: Methodology, Formal analysis, Writing - Original Draft

Emile Tompa: Methodology, Writing - Review \& Editing

Peter Smith: Methodology, Writing - Review \& Editing

Ute Bültmann: Methodology, Writing - Review \& Editing

Silvia Bonaccio: Formal analysis, Writing - Review \& Editing

Lori Tucker: Formal analysis, Writing - Review \& Editing

Cameron Norman: Methodology, Writing - Review \& Editing

Cristina G. Bank: Methodology, Writing - Review \& Editing

Monique AM Gignac: Methodology, Formal analysis Writing - Review \& Editing,

\section{Acknowledgements}

We would like to acknowledge Ayesha Khan for their support with data analysis.

\section{References}

1. World Economic Forum. The future of jobs report 2020. Geneva: World Economic Forum 2021.

2. Russek H, Thornton J, Elias D. Yesterday's gone: Exploring possible futures of Canada's labour market in a post-COVID world. Toronto, ON: Brookfield Institute; 2021.

3. Schneider P, Bakhshi H, Armstrong $\mathrm{H}$. The Future of Skills: Trends impacting on UK employment in 2030. London: Nesta and. 2017.

4. Jetha A, Bowring J, Furrie A, Smith F, Breslin C. Supporting the transition into employment: a study of Canadian young adults living with disabilities. Journal of occupational rehabilitation. 2019;29(1):140-9.

5. Organisation for Economic Co-Operation and Development. The future of work 2020 [Available from: https://www.oecd.org/employment/future-of-work/.

6. Manyika J, Chui M, Miremadi M, Bughin J, George K, Willmott P, et al. A future that works: Automation, employment, and productivity

7. . Mckinsey Global Institute; January 2017.

8. Acemoglu D, Restrepo P. Robots and jobs: Evidence from US labor markets. Journal of Political Economy. 2020;128(6):2188-244. 
9. Baldwin R. The Globotics Upheaval: Globalization, Robotics, and the Future of Work: Oxford University Press; 2019. 304 p.

10. Jetha A, Shamaee A, Bonaccio S, Gignac MA, Tucker L, Tompa E, et al. Fragmentation in the Future of Work: A Horizon Scan Examining the Impact of the Changing Nature of Work on Vulnerable Workers. 2020.

11. Bick R, Hazan E, Khan H, Lacroix S, Sarrazin H, Welchman T. The future of work: Reskilling and remote working to recover in the 'next normal'2020. Available from:

https://www.mckinsey.com/business-functions/mckinsey-digital/our-insights/the-future-of-workreskilling-and-remote-working-to-recover-in-the-next-normal\#.

12. Acemoglu D, Restrepo P. Low-skill and high-skill automation. Journal of Human Capital. 2018;12(2):204-32.

13. Lamb CP, Doyle S. The Talented Mr. Robot: The Impact of Automation on Canda's Workforce: Brookfield Institute for Innovation+ Entrepreneurship; 2016.

14. Burgard SA, Lin KY. Bad jobs, bad health? How work and working conditions contribute to health disparities. American Behavioral Scientist. 2013;57(8):1105-27.

15. Benach J, Benavides FG, Platt S, Diez-Roux A, Muntaner C. The health-damaging potential of new types of flexible employment: a challenge for public health researchers. American journal of public health. 2000;90(8):1316-7.

16. Morris S, Fawcett G, Brisebois L, Hughes J. A demographic, employment and income profile of Canadians with disabilities aged 15 years and over, 2017. Ottawa, ON: Statistics Canada; 2018.

17. Mann DR, Honeycutt TC. Is timing everything? Disability onset of youth and their outcomes as young adults. Journal of Disability Policy Studies. 2014;25(2):117-29.

18. Mann DR, Wittenburg DC. Starting behind: Wage and employment differentials between young adults with and without disabilities. Journal of Disability Policy Studies. 2015;26(2):89-99.

19. Block S, Hennessy T. "Sharing economy" or on-demand service: A survey of workers and consumers in the Greater Toronto Area. . Toronto, ON: Canadian Centre for Policy Alternatives; 2017.

20. Varpio L, Ajjawi R, Monrouxe LV, O'Brien BC, Rees CE. Shedding the cobra effect: problematising thematic emergence, triangulation, saturation and member checking. Medical education. 2017; 51(1):40-50.

21. Miles M, Huberman A, Saldaña J. Qualitative data analysis: A methods sourcebook.: Sage publications; 2018.

22. Denzin N, Lincoln Y. The Sage handbook of qualitative research:: Sage; 2011.

23. QSR International Pty Ltd. NVivo qualitative data analysis software. . 10 ed2016.

24. Ahonen EQ, Fujishiro K, Cunningham T, Flynn M. Work as an inclusive part of population health inequities research and prevention. American journal of public health. 2018;108(3):306-11.

25. Arnett J. Emerging adulthood: The winding road from late teens through the twenties. New York, NY.: Oxford I lnivercitv Precc. $20 \cap 4$

Loading [MathJax]/jax/output/CommonHTML/jax.js

Page $19 / 20$ 
26. Jetha A, Gignac MA, Bowring J, Tucker S, Connelly CE, Proulx L, et al. Supporting arthritis and employment across the life course: a qualitative study. Arthritis care \& research. 2018;70(10):1461-8.

27. Martin J, Lewchuk W. The Generation Effect: Millennials, employment precarity and the 21 st Century workplace. . Hamilton, ON: Poverty and Employment Precarity in Southern Ontario; 2018.

28. Quinlan M, Mayhew C, Bohle P. The global expansion of precarious employment, work disorganization, and consequences for occupational health: a review of recent research. International journal of health services. 2001;31(2):335-414.

29. Agrawal A, Gans J, Goldfarb A. Prediction machines: the simple economics of artificial intelligence: Harvard Business Press; 2018.

30. MIT Technology Review Panel. Amid the covid-19 pandemic, shifting business priorities. MIT Technology Review 2020.

31. Kinder M, Ross M. Reopening America: Low-wage workers have suffered badly from COVID-19 so policymakers should focus on equity. The Brookings Institute; 2020.

32. Schwab K. The fourth industrial revolution: what it means, how to respond: World Economic Forum; 2016 [Available from: https://www.weforum.org/agenda/2016/01/the-fourth-industrial-revolutionwhat-it-means-and-how-to-respond/.

33. United Nations. Convention on the Rights of Persons with Disabilities (CRPD) 2019 [Available from: https://www.un.org/development/desa/disabilities/convention-on-the-rights-of-persons-withdisabilities.html

34. An Act to ensure a barrier-free Canada, (2018).

35. Bakhshi H, Downing J, Osborne M, Schneider P. The future of skills: employment in 2030. London: Pearson and Nesta; 2017.

36. Miner R. The great Canadian skills mismatch: People without jobs, jobs without people and more. Toronto, ON: Miner Management Consultants; 2014.

37. Moueddene K, Wauters P, Coppola M, Ansaloni V, Ivanova M, Paquette J. Expected skills needs for the future of work. UK: Deloitte; 2019.

38. Edwards JR, Cable DM. The value of value congruence. Journal of Applied Psychology. 2009;94(3):654.

39. Park HI, Monnot MJ, Jacob AC, Wagner SH. Moderators of the relationship between person-job fit and subjective well-being among asian employees. International Journal of Stress Management. 2011;18(1):67.

40. van Vianen AE. Person-environment fit: A review of its basic tenets. Annual Review of Organizational Psychology and Organizational Behavior. 2018;5:75-101.

41. Sandqvist JL, Henriksson CM. Work functioning: a conceptual framework. Work. 2004;23(2):147-57.

42. Hines A. Thinking About the Future: Guidelines for Strategic Foresight Washington; 2008. 